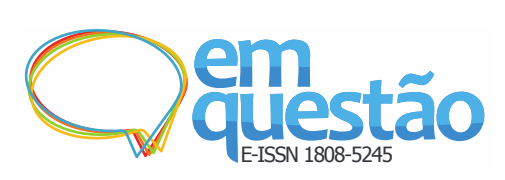

\title{
Ontologias para organização da informação em processos de transformação digital
}

\author{
Fabrício Martins Mendonça \\ Doutor; Universidade Federal de Juiz de Fora, Juiz de Fora, MG, Brasil; \\ fabricio.mendonca@ice.ufjf.br \\ Fernando Hadad Zaidan \\ Doutor; Instituto de Educação Tecnológica, Belo Horizonte, MG, Brasil; \\ fernando.zaidan@ietec.com.br
}

\begin{abstract}
Resumo: Atualmente, a aplicação das tecnologias digitais, pela sociedade contemporânea e nas organizações, tornou-se tão frequente e ampliada que é comum caracterizá-la como o processo de mudança conhecido como transformação digital. O objetivo deste artigo é discutir os conceitos e processos da transformação digital a serem utilizados como estratégias nas organizações, dando um enfoque principal ao uso e aplicação de ontologias, nesse contexto, e aos desafios atuais de aplicação. Nesta pesquisa, as ontologias são tratadas como instrumentos para representação e organização do conhecimento em diferentes domínios, no âmbito da Ciência da Informação. A metodologia de pesquisa utilizada foi exploratória com abordagem qualitativa, na qual se realizou o estudo da literatura científica, a seleção do estado da arte e a análise de caráter subjetivo. Os resultados indicaram que ontologias possibilitam representar as informações no processo de transição entre o projeto e o desenvolvimento do produto, atuando como a solução de problemas de interoperabilidade semântica. Ontologias são úteis, também, no processo de construção da nuvem de serviços de uma empresa, ao representarem conceitos básicos, terminologia e semântica de uma arquitetura orientada a serviços. Ao final, concluiu-se que ontologias são úteis nos processos de transformação digital e de desenvolvimento de produtos das empresas, pois tornam mais explícito o conhecimento adquirido de um certo domínio, possibilitam uma compreensão mais clara dos conceitos arquitetônicos integrados e fornecem mecanismos adicionais de inferência do conhecimento.
\end{abstract}

Palavras-chave: Transformação digital. Ontologias. Digitalização. Organizações.

\section{Introdução}

As ferramentas de tecnologia da informação e comunicação (TIC) são, muitas vezes, chamadas de tecnologias digitais e estão moldando a forma como as pessoas vivem, se comunicam, consomem e trabalham, quebrando as barreiras 
do tempo e do espaço (McDONALDS; RUSSEL-JONES, 2012). Atualmente, é fácil perceber o impacto das TIC sobre diversas áreas, tais como a indústria, o trabalho, a educação, os transportes e em tarefas do cotidiano das pessoas, que estão substituindo as maneiras tradicionais de realizar tarefas pelo uso de seus smartphones. Alguns exemplos: no lugar de jornais impressos as pessoas tem lido notícias em redes sociais ou em outros meios da internet; o deslocamento urbano tem sido realizado por serviços oferecidos por empresas como Uber, Cabify, EasyTaxi, ao invés dos táxis tradicionais; grande parte das transações bancárias é realizada por meio de internet banking; as locações de imóveis vem sendo realizadas através de sites, como $\operatorname{AirBnB}$, no lugar de imobiliárias; os canais do Youtube tem substituído muitos programas de TV; as compras em lojas físicas estão sendo substituídas por sites de e-commerce; e o uso de moedas virtuais, como por exemplo, os bitcoins, em paralelo com o tradicional dinheiro em papel.

Esse fenômeno da aplicação de tecnologias digitais na sociedade contemporânea, muitas vezes é referido como digitalização, que pode ser definida como "A prática de processos, conteúdo ou objetos que costumavam ser inteiramente físicos ou analógicos e transformando-os para ser primariamente ou inteiramente digital." (FICHMAN; SANTOS; ZHENG, 2014, p. 5, tradução nossa). Neste contexto, Zarzalejos (2016) acrescenta que as novas gerações nasceram com uma virtualidade - a tecnologia digital - que lhes empodera com possibilidades que revolucionaram o conceito de cidadania.

A digitalização é um tema bastante amplo e discutido na literatura da Ciência da Informação (CI), como pode ser comprovado em Alvarenga (2003), Gómez (2004), Barreto (2005), D’Andréa (2006), Fichman, Santos e Zheng (2014), Zarzalejos (2016), Toolboom (2016). Atualmente, o processo de digitalização nas organizações modernas e na sociedade tornou-se tão frequente e ampliado, que um novo conceito foi introduzido para caracterizar as mudanças tecnológicas inseridas na sociedade e em suas organizações - a chamada transformação digital. Entende-se que a Ciência da Informação possui um papel importante frente aos acontecimentos e consequências da digitalização e, consequentemente, da transformação digital. 
Muitas definições têm sido enunciadas para definir o termo transformação digital, principalmente por ser um conceito novo. De maneira geral, as definições caminham para uma mesma direção e podem ser bem representadas de acordo com Tolboom (2016), para quem a transformação digital é o processo de mudança realizado a partir do uso das chamadas tecnologias sociais, móveis, analíticas e tecnologias em nuvem (em inglês Social, Mobile, Analytics and Cloud, SMAC), que afetam significativamente três ou mais dimensões: no nível individual, empresarial e/ou social. Esse processo de mudança, que coloca a tecnologia em um papel central dentro de uma organização e da sociedade como um todo, é um grande desafio para as empresas e os indivíduos.

Diante do exposto, o objetivo deste artigo é discutir conceitos importantes a serem utilizados como estratégia nas organizações, para se prepararem e se adequarem ao necessário processo de transformação digital. Especificamente, será abordado o papel das ontologias no processo de transformação digital das empresas, destacando as possibilidades de aplicação das ontologias nesse contexto e os desafios atuais para aplicação.

Cabe elucidar, desde já, que o conceito de ontologia aqui adotado se refere ao seu uso comum no âmbito da CI, ou seja, ontologia é compreendida como um instrumento para a organização e representação da informação, capaz de capturar, mapear e compartilhar o conhecimento de diferentes domínios do conhecimento.

Além desta introdução, a sequência deste artigo inclui a metodologia de pesquisa na seção 2 . A seção 3 realiza a revisão de literatura, destacando os dois temas principais da pesquisa: transformação digital e ontologias. A seção 4 discute o papel das ontologias no processo de transformação digital das organizações, destacando duas áreas atuais de aplicação: ontologias no processo de desenvolvimento de produtos e ontologias na construção da nuvem de serviços em uma organização. Por fim, a seção 5 apresenta considerações finais. 


\section{Metodologia de pesquisa}

A presente pesquisa classifica-se como exploratória, o que Lakatos e Marconi (2017) esclarecem como as que determinam as descobertas científicas, elucidações de fenômenos ou mesmo explicações que não eram aceitas, apesar de evidentes. Buscou-se descobrir ideias e intuições, na tentativa de maior familiaridade dos autores com o tema pesquisado.

Quanto à abordagem, conduziu-se este estudo de forma qualitativa. Michel (2015) diz que este tipo de pesquisa se caracteriza pela interpretação dos fenômenos à luz do contexto, do tempo, dos fatos e da análise de todas as interferências. Segundo esta autora, o pesquisador deve interpretar a realidade com base em teorias existentes para que possa dar significado às respostas.

Michel (2015) confirma a escolha qualitativa para este estudo na medida em que se realizou uma análise de caráter subjetivo; discutiu-se, correlacionouse e interpretou-se situações e fatos; analisou-se e apresentou-se resultados predominantemente no formato de texto corrido; concluiu-se através de análises coerentes; e por fim, utilizou-se da participação ativa dos pesquisadores por meio da compreensão e interpretação.

O percurso metodológico da Figura 1 retrata como os autores conduziram o estudo.

Figura 1 - Percurso metodológico da pesquisa.

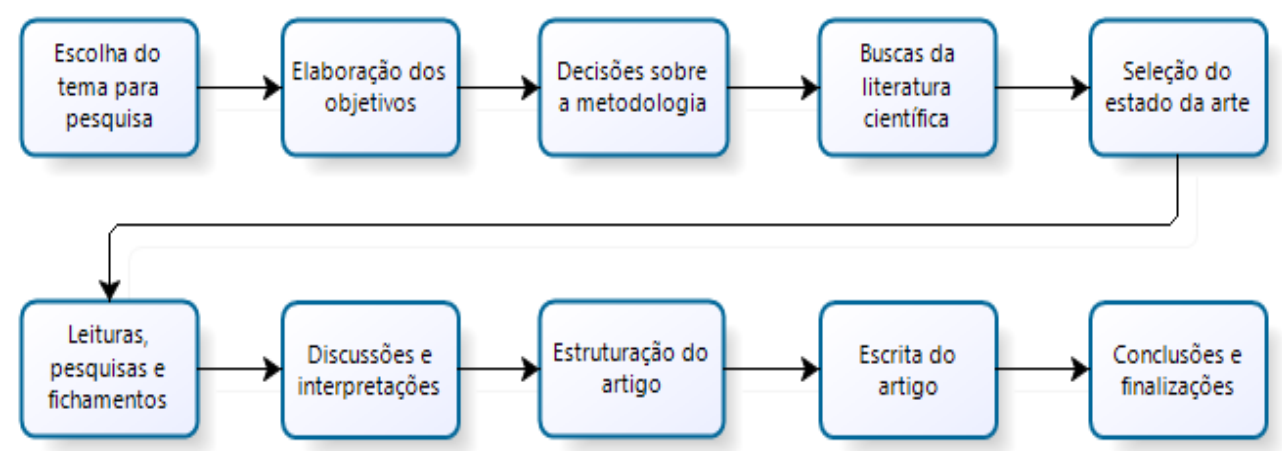

Fonte: Elaborado pelos autores. 
Portanto, realizou-se um estudo da literatura científica e o estado da arte, que forneceu subsídios para compreensão dos assuntos abordados, além de sólido embasamento para o alcance do objetivo proposto.

\section{Revisão de literatura}

A presente seção apresenta a revisão de literatura realizada nesta pesquisa. Dividiu-se esta seção em duas: subseção 3.1 - transformação digital, que explica esse novo conceito e apresenta os desafios impostos às organizações pela transformação digital; e subseção 3.2 - ontologias, que descreve conceitos e aplicações relacionados às ontologias, destacando sua função como instrumento de organização e representação da informação.

\subsection{Transformação digital}

Atualmente, ao se pesquisar sobre transformação digital na internet e em outros meios de comunicação, percebe-se um grande interesse pelo tema e nos estudos sobre seu crescimento no cenário empresarial. Toolbom (2016), por exemplo, afirma que as pesquisas no Google pelo termo transformação digital produziram mais de 23,5 milhões de acessos desde outubro de 2015 (até 2016). Já em uma previsão da MarketsandMarkets (2015), espera-se que o mercado de transformação digital global cresça de U\$ 150 bilhões para U\$ 369 bilhões nos cinco anos subsequntes (até 2020), demonstrando a forte tendência desse mercado.

Apesar do grande interesse nos estudos sobre transformação digital, ao pesquisar pelo tema na literatura verdadeiramente científica, é possível perceber que ainda existem poucos trabalhos sobre tal. Em razão disso, a presente pesquisa busca contribuir com a área ao discutir conceitos diretamente relacionados com transformação digital, especialmente a aplicação de ontologias no âmbito organizacional.

Patel e McCarthy (2000) foram os pioneiros ao mencionar o conceito de transformação digital, embora não tenham definido o termo. De acordo com Tolboom (2016), desde esta primeira citação até os dias atuais, a literatura 
apresentou algumas definições, holísticas por natureza. Como exemplo, tem-se em Westerman, Calmejane e Bonnet (2011, p. 5), que a transformação digital é "o uso da tecnologia para melhorar radicalmente o desempenho ou alcance das empresas”. Entretanto, é preciso identificar definições mais específicas para o termo, como a de Toolbom (2016) - citada anteriormente - na qual transformação digital pode ser compreendida como o processo de mudança realizado a partir do uso das tecnologias sociais, móveis, analíticas e em nuvem.

Além disso, é importante destacar também que a transformação digital não implica em alterações progressivas graduais nos níveis individual, empresarial e social, mas sim em mudanças radicais nestes níveis, devido às tecnologias digitais. Estas tecnologias sociais, móveis, analíticas e em nuvem são reconhecidas como aquelas capazes de gerar inovações empresariais que afetam a vida social e econômica (BHARADWAJ et al., 2013; FITZGERALD et al., 2013).

Adicionalmente, Frank, Roehrig e Pring (2014) afirmam que as tecnologias SMAC representam a quinta onda de Tecnologia da Informação (TI) corporativa, de forma que estamos vivenciando a transição entre a quarta e quinta onda de TI. Em cada onda de TI, o número de dispositivos de conexão cresce dez vezes, resultando em um número total de pelo menos 25 bilhões de dispositivos conectados até 2020, segundo estimativas da Gartner (2014). Em um futuro próximo, será possível assistir novas ondas de tecnologias digitais que irão direcionar as inovações. Assim, as tecnologias digitais que se enquadram no conceito de transformação digital poderão mudar. Mas, atualmente, essas tecnologias são as sociais, móveis, analíticas e em nuvem.

Mudanças radicais são uma medida bastante arbitrária para determinar se uma mudança é transformacional ou não. Para tanto, pode-se recorrer à Lucas et al. (2013) que fornecem uma medida quantitativa para definir se uma mudança orientada pela tecnologia é considerada transformacional ou não. Os autores apresentam sete dimensões diferentes para classificar as transformações orientadas pela tecnologia, apresentadas no Quadro 1. Quando três das dimensões são significativamente impactadas, a tecnologia é considerada transformacional. 
Quadro 1 - Dimensões para classificação da transformação como digital

\begin{tabular}{|c|c|c|}
\hline & Dimensão & Limite/Critério de Impacto \\
\hline 1 & Processos & $\begin{array}{l}\text { Mais da metade das etapas dos processos individuais ou } \\
\text { organizacionais é mudado. }\end{array}$ \\
\hline 2 & $\begin{array}{l}\text { A criação de } \\
\text { novas } \\
\text { organizações }\end{array}$ & $\begin{array}{l}\text { A mudança vale mais de US\$ } 100 \text { milhões ou mudam } \\
\text { duas horas de comportamento individual por dia. }\end{array}$ \\
\hline 3 & $\begin{array}{l}\text { Mudanças nos } \\
\text { relacionamentos } \\
\text { entre } \\
\text { organizações e } \\
\text { clientes }\end{array}$ & $\begin{array}{l}\text { Mais da metade dos contatos; ou dobro dos contatos } \\
\text { dos indivíduos e/ou organizações; ou mudança de duas } \\
\text { horas no comportamento individual por dia. }\end{array}$ \\
\hline 4 & $\begin{array}{l}\text { Mudanças no } \\
\text { mercado }\end{array}$ & $\begin{array}{l}\text { Mudança de pelo menos metade dos vendedores, } \\
\text { entrada ou saída de um mercado servido e/ou criação de } \\
\text { um novo mercado (mais de US \$100 milhões). }\end{array}$ \\
\hline 5 & $\begin{array}{ll}\text { Mudanças } & \text { na } \\
\text { experiência } & \text { do } \\
\text { usuário } & \end{array}$ & $\begin{array}{l}\text { Uma mudança de } 2 \text { horas por dia na experiência do } \\
\text { usuário. }\end{array}$ \\
\hline 6 & $\begin{array}{ll}\text { Mudanças } & \text { na } \\
\text { quantidade } & \text { de } \\
\text { clientes } & \end{array}$ & $\begin{array}{l}\text { Se uma organização passa a atender pelo menos } 50 \% \text { a } \\
\text { mais de clientes. }\end{array}$ \\
\hline 7 & $\begin{array}{l}\text { Impacto } \\
\text { perturbador }\end{array}$ & $\begin{array}{l}\text { Se um ou mais concorrentes forem forçados a operar } \\
\text { em perdas e/ou a sair de mercados ou a uma redução de } \\
\text { mais de US } \$ 100 \text { milhões em custos de transações. }\end{array}$ \\
\hline
\end{tabular}

Fonte: Adaptado de Lucas et al. (2013, p. 19).

Por fim, destaca-se a necessidade atual de que empresas, indivíduos e sociedade, estejam preparados para este contexto dinâmico, impulsionado e pressionado pela transformação digital. Nesse sentido, Santos e Massó (2016) afirmam que a transformação digital deve ser uma prioridade em nossas agendas e na agenda de qualquer país, simultaneamente à preocupação de adequar-se à competitividade que o mundo de hoje nos exige naturalmente. Zarzalejos (2016) corrobora esse pensamento, afirmando que o grau de modernização conjunta de um país, de sua sociedade e de seu sistema produtivo, já é baseado em seu grau de digitalização. Tempos atrás, falava-se em modernização de serviços bancários e comerciais, especificamente -, mas a digitalização foi naturalizada na indústria, tanto que o assunto foi tema central do Fórum Econômico Mundial de Davos (WORLD ECONOMIC FORUM, 2016). Esse fenômeno tem sido chamado de "a quarta revolução industrial", após a primeira da mecanização, a 
segunda da eletricidade, e a terceira das tecnologias da informação e comunicação (ZARZALEJOS, 2016).

Waleska (2016) ressalta que são necessários modelos de inovação que orientem a estratégia, a cultura, os processos e as capacidades de uma organização em direção a um projeto de estratégia digital clara, mas não apenas isso. A autora também destaca que são necessários líderes que defendam a mudança cultural em direção à transformação digital como uma via imprescindível para superar o novo mapa de desafios configurados após a crise. Como exemplo nesse cenário, na última década, algumas organizações, como o Google, Netflix, Amazon e Apple, adaptaram, com sucesso, suas tecnologias digitais, levando a uma expansão significativa destas empresas no mercado. Enquanto outras empresas, como Borders, Blockbusters e Kodak, não conseguiram fazê-lo e ficaram obsoletas ou acabaram desaparecendo. Atualmente, as organizações, de maneira geral, sentem-se pressionadas a mudar para atender às demandas dos clientes, gerando valor, enfrentando pressões competitivas e, assim, sofrem as chamadas iniciativas de transformação digital (WESTERMAN; CALMEJANE, BONNETT, 2011).

É preciso destacar, também, que, quando uma organização utiliza uma nova tecnologia digital no seu negócio, não significa, necessariamente, que esta organização sofre uma transformação digital, ou seja, uma mudança radical fundamental. É necessário classificar a dimensão da mudança em razão da tecnologia digital adotada, usando, por exemplo, uma classificação da mudança tal como proposto em Lucas et al. (2013).

Waleska (2016) mostra que as organizações devem se preparar para uma substituição de altos investimentos de capital por custos operacionais razoáveis, fazendo a conversão dos recursos de computação e plataformas tecnológicas em uma utilidade. Tal como se contrata, atualmente, a eletricidade ou o serviço de água, as organizações, e mesmo os indivíduos, devem contratar capacidades tecnológicas como serviço, a fim de permitir que se alcance eficiência, segurança, escalabilidade e integração rápida. A respeito dessa nova forma de pensar tecnologias como serviços, Datta (2016) destaca que se vivencia a transição destes produtos como itens a serem vendidos para a criação de um 
ecossistema de serviços em torno do produto, de forma a vender o serviço como modelo de pagamento por uso. Nesse sentido, a transformação digital inclui o estabelecimento de formas para monitorar, promover, conectar, rastrear e viabilizar o relacionamento com o cliente não apenas uma vez, mas durante o tempo de vida do produto. Não é suficiente apenas avaliar a venda do produto ou a não entrega deste, pois a gestão do ciclo de vida do produto evolui para uma gestão digital com qualidade de serviço - do inglês Quality of Service (QoS). Aliás, a QoS emerge como a métrica apropriada para avaliar a satisfação do cliente. Se as métricas de QoS forem mantidas pelo provedor ou fabricante do serviço, o cliente deverá pagar o nível de QoS associado ao serviço do produto definido em contrato.

Do ponto de vista social, é preciso aceitar como necessidade básica e urgente para os países, fornecer o acesso às tecnologias para todos, especialmente às populações menos favorecidas. Além disso, esse acesso deve ser acompanhado de educação apropriada, para gerar oportunidades reais de inclusão e competitividade que permitam colaborar com o encerramento de uma lacuna que, mais que uma exclusão digital, é uma lacuna social.

\subsection{Ontologias: conceitos e aplicações}

Ontologia é um tema, a muito, estudado pela Filosofia, que a considera um ramo da metafísica que se preocupa com as coisas que existem (BLACKBURN, 1996). Do ponto de vista da CI, ontologia é compreendida como um instrumento para a organização e representação da informação, capaz de capturar, mapear e compartilhar o conhecimento de domínios específicos. Na literatura da área, uma definição bastante comum sobre ontologia é a de uma especificação explícita e formal de uma conceitualização compartilhada (GRÜBER, 1993; BORST, 1997), onde especificação explícita refere-se a conceitos, atributos, relações e axiomas explicitamente definidos. Nesse contexto, formal significa legível por máquinas (computadores), conceitualização pode ser entendida como um modelo abstrato de algum fenômeno do mundo real e compartilhada significa conhecimento consensual. 
A conceitualização é uma das mais importantes etapas do processo de construção de ontologias, porque é nela que se realizam atividades como identificação, análise e negociação dos conceitos de um determinado domínio resultando nos modelos conceituais do mesmo (PEREIRA; SOARES, 2008). A conceitualização é, em geral, intermediada por um responsável pela modelagem do domínio (analistas de sistemas, analistas de negócio, desenvolvedores de ontologias, entre outros), e realizada por especialistas (médicos, engenheiros, advogados, entre outros) em domínios do conhecimento específicos, que são de interesse para o problema analisado. Os especialistas fornecem a expertise para o entendimento e modelagem das entidades e das relações que serão representados na ontologia do domínio. É importante destacar, também, os componentes básicos de uma ontologia, os quais são: (1) classes: organização dos conceitos de um domínio, dispostas através de uma taxonomia; (2) relações: representam o tipo de interação entre as classes do domínio; (3) axiomas: regras formais usadas para restringir a interpretação e o uso dos termos envolvidos, geralmente especificadas em uma linguagem formal da lógica; (4) instâncias: exemplos ou casos particulares das classes, usadas para representar objetos específicos; (5) questões de competência: perguntas elaboradas para serem respondidas pela ontologia em construção, que permitem definir o escopo e as características da ontologia, além de especificar tarefas e os problemas que ela pode solucionar (GRÜBER, 1993; USCHOLD; GRUNINGER, 1996).

No que diz respeito à relação entre ontologias e a CI, o estudo de ontologias na organização e representação do conhecimento surgiu como um ramo de pesquisa no final dos anos 1980, propondo ser uma alternativa aos demais instrumentos de representação, tais como: vocabulários controlados, taxonomias e tesauros. Porém, somente na década de 1990, a partir dos trabalhos de Soergel (1997) e de Vickery (1997), começam a surgir pesquisas sobre ontologias na área de CI, aplicadas, a princípio, à Biblioteconomia. Atualmente, as ontologias têm sido bastante utilizadas no âmbito das pesquisas da CI, utilizadas como um instrumento alternativo e complementar aos demais instrumentos de representação da área, uma vez que as ontologias possuem uma maior capacidade de expressividade do conhecimento formal, por utilizarem 
formalismos da Lógica para representar o conhecimento de um dado domínio.

Dentre as várias aplicações de ontologias na área da CI, pode-se citar: (1) suporte à extração de informação de bibliotecas ou da literatura científica disponível em diversas fontes na web (VICKERY, 1997; SMITH, 2004); (2) integração automática de um conjunto de vocabulários padronizados ou dicionários de dados, relacionados a um domínio específico, que auxiliam na construção de um único vocabulário padrão (SMITH, 2004; SCHULZ et al., 2009); (3) tradução de linguagem natural, auxiliando no processo de resolução dos problemas de ambiguidade (VICKERY, 1997); (4) integração de bancos de dados, de softwares ou de modelos de negócio das empresas (SMITH, 2004); (5) suporte no desenvolvimento de sistemas que lidam com informações complexas e heterogêneas, úteis para as distinções semânticas humanas, que devem ser implementadas em sistemas especialistas (CASTILLA, 2007).

Como forma de ilustrar uma aplicação atual de ontologias, toma-se um exemplo da área biomédica, onde as ontologias têm sido utilizadas como forma de padronização, integração e melhoria das muitas terminologias médicas disponíveis. Um bom exemplo nesse domínio é o portal semântico da Open Biological and Biomedical Ontologies (OBO) Foundry (OPEN BIOLOGICAL AND BIOMEDICAL ONTOLOGY, 2017), o qual se tornou uma importante fonte de ontologias biomédicas online de domínio público, para utilização por parte de profissionais da área biomédica e por especialistas em informação (SMITH et al., 2007). Atualmente, a OBO Foundry compreende aproximadamente 300 ontologias, tais como: anatomia humana, através do Foundational Model Anatomy; bioquímica, com a Chemical Entities of Biological Interest; tipos de células, através da Cell Ontology; genética, por meio da Gene Ontology; entre outras. Além de uma ontologia de alto nível de fundamentação que é a Basic Formal Ontology.

Outra aplicação muito relevante de ontologias é seu uso no contexto da web semântica (web de dados ou web 3.0). A web semântica pode ser definida como a extensão da web atual (web sintática ou web 2.0), cujo objetivo é desenvolver meios para que as máquinas possam servir aos humanos de maneira mais eficiente (BERNERS-LEE; HENDLER; LASSILA, 2001), de tal forma 
que as buscas dos usuários por uma dada informação recuperem informações integradas, as mais precisas possíveis e sem ambiguidades, além da possibilidade de inferência/dedução de informações por parte das máquinas.

$\mathrm{Na}$ web semântica, existe a necessidade de uma metodologia para a definição global de termos e de relações entre as partes, com vistas ao entendimento universal. A mesma necessidade é almejada para os dados heterogêneos. As ontologias são modelos conceituais que capturam e explicitam o vocabulário utilizado em aplicações semânticas e servem como base para garantir uma comunicação livre de ambiguidades. Nesse sentido, as ontologias podem ser consideradas um dos pilares da web semântica (W3C, 2017), oferecendo um conjunto de definições de conceitos e do relacionamento entre eles, com compromisso no compartilhamento semântico. Ontologias são a língua franca da web semântica (BREITMAN, 2005).

Além disso, no cerne dos conceitos da web semântica, está a interoperabilidade, a qual pode ser compreendida como a capacidade de diversos sistemas e organizações trabalharem em conjunto (interoperar) de modo a garantir que pessoas, organizações e sistemas computacionais interajam para trocar informações de maneira eficaz e eficiente (BRASIL, 2017). Neste contexto, de acordo com Villalobos e Silva (2010), a ontologia cumpre um papel importante, aumentando o potencial informacional entre os sistemas. $\mathrm{O}$ conceito de interoperabilidade emerge da necessidade dos dados, primeiramente produzidos de forma independente e depois acarretando em heterogeneidade, terem uma estrutura uniforme e integrada, permitindo o compartilhamento. Tratar a interoperabilidade é uma das principais metas atuais do consórcio $\mathrm{W}_{3} \mathrm{C}^{1}$, que vem se dedicando ao desenvolvimento de padrões para avançar rumo à excelência em termos de interoperabilidade.

Para assegurar que a informação seja representada de maneira formal e explícita, permitindo inferências ao conteúdo representado, as ontologias são expressas em linguagens formais específicas no contexto da web. Os formatos mais utilizados para representação formal das ontologias são as linguagens Resource Description Framework (RDF) e Ontology Web Language (OWL), ambas criadas e padronizadas pelo $\mathrm{W} 3 \mathrm{C}$. 
O modelo RDF fornece uma semântica simplificada, com boa representação para o tratamento de metadados, mas não fornece subsídios necessários para a expressividade exigida de uma ontologia (MIKA, 2007). Já a linguagem OWL permite a descrição dos aspectos semânticos dos termos utilizados e seus respectivos relacionamentos, favorecendo uma representação mais abrangente da RDF, contemplando a interoperabilidade e possibilitando a construção de ontologias. OWL e RDF incorporam as novas necessidades de representação de sistemas por ontologias. (RAMALHO; VIDOTTI; FUJITA, 2007). Pode-se concluir que RDF e OWL possuem semântica formal, assegurando que uma linguagem seja interpretada sem ambiguidades, ponto crítico no compartilhamento de informações na web.

\section{O papel das ontologias para transformação digital}

Como destacado, as ontologias cumprem bem o papel de representar a informação em contextos digitais, tal como na web semântica, permitindo que as máquinas façam inferências e interpretações do conhecimento representado. Nesse contexto, torna-se ainda necessário clarificar como as ontologias podem contribuir para o processo de transformação digital nas organizações e nos níveis individual e social, objetivo central deste estudo. O propósito dessa seção é, justamente, discorrer sobre o papel das ontologias para transformação digital. É importante destacar, também, que não se pretende esgotar o assunto, cujo escopo é amplo, e o objetivo desta pesquisa é introduzir o tema de forma a alertar para sua relevância no cenário atual.

A fim de explicar o papel das ontologias para transformação digital, optou-se por destacar duas áreas de aplicação direta de ontologias, que contribuem para esse processo: i) ontologias que podem ser utilizadas no processo de desenvolvimento de produtos (PDP), de forma a colaborar com o tratamento de problemas relacionados à interoperabilidade semântica (SZEJKA et al., 2016); ii) ontologias que podem ajudar na construção de uma nuvem de serviços apropriada para as empresas (JAVAID et al., 2017). As duas subseções seguintes concentram-se em explicar estes campos de aplicação. 


\subsection{Ontologias no processo de desenvolvimento de produtos (PDP)}

Com relação à primeira área de aplicação, sabe-se que o processo de PDP é complexo, e envolve diferentes etapas multidisciplinares e estruturadas (planejamento, projeto/design, construção/desenvolvimento, produção, manutenção e descontinuidade). Na execução de tais etapas, informações de diferentes áreas do conhecimento são compartilhadas e trocadas simultaneamente por grupos heterogêneos, que podem estar atuando internamente na empresa ou mesmo fora dela. De acordo com Rozenfeld et al. (2006), as atividades de projeto e desenvolvimento do produto são as mais custosas, representando $85 \%$ do custo final. O conjunto de atividades transdisciplinares do PDP e os múltiplos pontos de vista sobre o desenvolvimento do produto geram, nesse processo, obstáculos semânticos que causam problemas de interoperabilidade (SZEJKA et al., 2016).

Nesta mesma perspectiva, Smith e Welty (2001) afirmam que a inconsistência na modelagem conceitual de sistemas de informação tem sido a causa dos atuais problemas de interoperabilidade entre sistemas. Sobre tais problemas, Fonseca e Martin (2007) acrescentam o fato de que a maioria dos esquemas conceituais, resultantes da atual prática de modelagem conceitual, são construídos para fins específicos de um dado sistema de informação em desenvolvimento. Assim, o propósito prático de um esquema conceitual é definir, restringir e limitar o que deve ser registrado e manipulado por esse sistema de informação, sem manter o compromisso com o que de fato existe na realidade de um dado domínio.

Atualmente, a complexidade do PDP tem aumentado, para atender às demandas e necessidades urgentes de clientes mais exigentes (SZEJKA et al., 2016), da mesma forma que o aumento do volume e diversidade dos dados produzidos nas organizações e, especialmente, na web, vem provocando o crescimento dos problemas de interoperabilidade. Diante desse cenário, esta pesquisa procura alertar para o fato de que processos tradicionais de desenvolvimento de produto e a prática atual de modelagem conceitual de sistemas (por exemplo, o uso apenas de modelos da Unified Model Language- 
UML) podem não conseguir acompanhar as demandas, atuais e futuras, inseridas no contexto da transformação digital.

Na presente pesquisa, argumenta-se a favor do uso de ontologias formais como uma solução apropriada para endereçar os problemas de interoperabilidade semântica verificados ao longo do PDP. Dessa forma, organizações e indivíduos serão beneficiados no tratamento de problemas desta natureza, que poderão surgir no processo de transformação digital.

Szejka et al. (2016) complementam que as ontologias, atualmente, representam a melhor forma de compartilhamento de informações no processo de transição entre o projeto e o desenvolvimento do produto, auxiliando, também, na verificação de conformidade dos requisitos com o produto em desenvolvimento. Além disso, as ontologias ajudam a tornar mais explícito o conhecimento adquirido de um determinado domínio, promovendo o compartilhamento de informações e possibilitando sua integração entre sistemas de informação (SMITH et al., 2007; FONSECA; MARTIN, 2007).

Szejka et al. (2016) destacam, ainda, alguns trabalhos relacionados ao o uso de ontologias nesta área de aplicação, afirmando que existe uma tendência atual para explorar o uso de linguagens de ontologia da web semântica, como a OWL, com o propósito de modelar o conhecimento dos produtos em desenvolvimento. Nessa direção, estes autores propuseram o conceito de um Sistema de Construção e Design de Produto Interoperável (Interoperable Product Design and Manufacturing System - IPDMS), que suporta a troca de informações em uma forma computacional, em três fases diferentes do PDP, baseado em um conjunto de ontologias do domínio da engenharia e abordagens de mapeamento semântico. Um experimento preliminar do IPDMS foi realizado em Szejka et al. (2016), usando um caso de teste para compartilhar informações do projeto para a fabricação de um plástico de moldagem por injeção.

O IPDMS é apenas um dos muitos exemplos que podem ser encontrados na modelagem de sistemas baseados em ontologias. Concluindo esta área de aplicação, pode-se afirmar que, atualmente, os modelos orientados para a interoperabilidade semântica são necessários, de forma que forneçam o equilíbrio e integrem o trabalho de domínio múltiplo em equipes de 
desenvolvedores com diferentes pontos de vista, permitindo a troca de informações, em alguma forma computacional, das diferentes etapas do PDP.

\subsection{Ontologias na construção da nuvem de serviços}

Uma das tarefas essenciais para que as organizações, e mesmo os indivíduos, se preparem para o processo de transformação digital, é que ambos devem contratar capacidades tecnológicas como serviço, a fim de permitir que se alcance eficiência, segurança, escalabilidade e integração rápida. A construção de uma nuvem de serviços para a organização é uma das premissas básicas para sua transformação digital.

Cabe, inicialmente, discorrer sobre serviços, cuja ideia de fornecimento e contratação pelo uso é antiga quando se trata de serviços básicos, tais como água e eletricidade. Já a contratação de tecnologias como serviços é um conceito relativamente novo e teve sua origem em pesquisas e aplicações na área de computação. O termo usado em computação para essa modalidade de contratação é Software como Serviço (do inglês Software as Service - SaaS), que se caracteriza como uma forma de fornecer funcionalidades em um servidor remoto, com acesso de clientes por meio de um navegador web (por exemplo, Firefox, Google Chrome, Internet Explorer, entre outros). O servidor mantém os dados e o estado do cliente durante uma sessão de interação, como por exemplo, operações feitas em sessões longas na edição de um documento no Google Docs $^{2}$.

No fornecimento de SaaS, o software é implantado em um servidor (ou em vários servidores) e é acessado através de um navegador web instalado nas máquinas clientes. Esse software é de propriedade e gerenciado por um provedor de software, não pelas organizações que o utilizam. Os usuários podem pagar pelo software de acordo com a quantidade de uso que fazem dele ou através de uma assinatura periódica. Às vezes, o software é livre para uso, mas, nestes casos, os usuários devem concordar em aceitar anúncios que financiam o SaaS (SOMMERVILLE, 2011). 
Diversos exemplos de aplicações de SaaS podem ser encontrados atualmente no mercado, por exemplo: serviços de hospedagem em nuvem (iCloud, Amazon Web Services, WordPress, entre outros), serviços de armazenamento de arquivos (Google Drive, One Drive, Drop Box, entre outros), serviços de backup (Amazon Single Storage Service, Amazon Glacier, iCloud, entre outros), aplicativos de uso geral (Google Docs na edição de documentos, Draw.io na modelagem de sistemas, entre outros).

A implementação de software como serviço só é possível graças à construção de uma Arquitetura Orientada a Serviços (do inglês Service Oriented Architecture - SOA), que foi proposta no Gartner Group por Schulte e Natis (SOMMERVILLE, 2011), em uma análise de experiência com diversos clientes que passaram a utilizar SOA no lugar de uma arquitetura cliente-servidor. Desde então, arquiteturas orientadas a serviços evoluíram e passaram a ser muito utilizadas como estratégia para organizar as soluções de TI, se tornando um padrão. Por meio de serviços orientados por funcionalidades do negócio, utilizar SOA em um ambiente de infraestrutura de TI, suporta as necessidades do negócio de forma dinâmica (SOMMERVILLE, 2011).

A existência de uma grande variedade de serviços em nuvem, disponíveis a preços acessíveis, e suas potencialidades em impulsionar os negócios das empresas, são fatos claramente reconhecidos pelo mercado e pelos profissionais da área. A grande questão é: como uma empresa deve montar sua estratégia para migrar seus serviços para a nuvem e quais outros serviços em nuvem contratar, de forma que todo o potencial da nuvem possa ser explorado?

No presente artigo, defende-se o argumento de que as ontologias são extremamente úteis no processo de construção da nuvem de serviços de uma empresa, auxiliando gestores nessa tarefa essencial para o processo de transformação digital na empresa. Zimmermann et al. (2015), por exemplo, destaca que as ontologias corporativas representam um vocabulário comum, que inclui conceitos básicos, terminologia e semântica de SOA, para os arquitetos empresariais que precisam compartilhar suas informações com base em conceitos explicitamente definidos. Tal representação possibilita uma 
compreensão clara dos conceitos arquitetônicos integrados e fornece, ainda, mecanismos adicionais de representação e inferência do conhecimento.

Nesse cenário, as ontologias têm sido desenvolvidas como representações semânticas de SOA, de forma a fornecer uma base para facilitar a navegação e a simulação dentro do complexo espaço das arquiteturas empresariais. Alguns exemplos práticos, deste tipo de ontologia, que merecem destaque são: (1) Service-Oriented Architecture Ontology (SOA) desenvolvida pelo Open Group (OPEN GROUP, 2018); (2) ontologia da Enterprise Services Architecture Reference Cube (ESARC) (ZIMMERMANN et al., 2015); (3) ontologia desenvolvida para a linguagem e procedimento de modelagem Latter (JAVAID et al., 2017). A seguir será explicada cada uma dessas três ontologias.

A ontologia SOA apresenta conceitos básicos de uma arquitetura genérica orientada a serviços como classes e propriedades, especificada na linguagem OWL, com o objetivo de promover o entendimento comum de SOA e facilitar a adoção desse tipo de arquitetura pelas empresas (OPEN GROUP, 2018). Tal ontologia define conceitos, terminologia e semântica de SOA e é destinada, principalmente, para arquitetos empresariais, gestores, arquitetos de software e desenvolvedores. Inclui também diagramas UML que ilustram graficamente as classes e propriedades da ontologia. Os diagramas UML são destinados apenas a explicações, contudo, sabe-se que são construções úteis para entender o domínio modelado da arquitetura SOA.

Ainda sobre a ontologia SOA, é importante ressaltar que ela define as relações entre os termos de uma arquitetura SOA, mas não prescreve exatamente como eles devem ser aplicados. Os exemplos fornecidos no padrão SOA descrevem uma maneira pela qual a ontologia poderia ser aplicada em situações práticas, porém, diferentes aplicações da ontologia para as mesmas situações são possíveis. A instanciação precisa da ontologia em situações práticas particulares, é uma questão para os usuários da ontologia, e essa instanciação será válida se os conceitos definidos pela ontologia forem corretamente aplicados.

A ESARC compreende uma estrutura de categorização de arquitetura empresarial SOA, que estabelece um esquema de classificação para modelos de arquitetura corporativa, como instrumento orientador para decisões em pontos 
de vista de engenharia arquitetônica (ZIMMERMANN et al., 2015). A base da ESARC é uma ontologia de domínio que foi desenvolvida a partir da ontologia SOA, tal que as classes genéricas são da ontologia SOA e as classes finais/específicas são da ontologia ESARC. De acordo com seus autores, o objetivo com a ESARC é navegar mais facilmente no complexo espaço das estruturas de gerenciamento de arquitetura corporativa e permitir decisões sustentadas pela semântica representada. É importante destacar, também, que a ESARC vem integrando seus modelos para Internet das Coisas (do inglês Internet of Things $-\mathrm{IoT}^{3}$ ).

Por fim, Latter é um método de modelagem direcionado às pequenas e médias empresas, para adaptar e/ou ampliar seu modelo de negócio através de serviços digitais (JAVAID et al., 2017). Latter consiste em uma linguagem de modelagem (sintaxe, semântica e notação), um procedimento de modelagem (etapas que são aplicadas para desenvolver um modelo) e mecanismos que são aplicados à linguagem e ao procedimento de modelagem. A parte semântica é alcançada com o uso de ontologias. O método de modelagem desenvolvido deve ser interpretável tanto pelo homem quanto pela máquina. A interpretação pela máquina ocorre com o objetivo de promover o alinhamento consistente de negócios e TI por meio da automação. Como as relações e dependências na arquitetura corporativa são complexas, a inteligibilidade das máquinas pode ajudar a capturar o conhecimento e argumentar sobre isso. Desta forma, a almejada automação é alcançada usando o conceito de ontologias corporativas.

Diante do que foi exposto nesta seção, pode-se concluir que a construção da nuvem de serviços de uma organização é uma etapa essencial e indispensável para seu processo de transformação digital. E não apenas isso, também é fundamental que se desenvolva ontologias que forneçam suporte para a criação da nuvem. Recomenda-se a construção de ontologias, a fim de melhorar o alinhamento do conhecimento e dos serviços dentro das empresas, bem como no ambiente externo (interorganizações e com as comunidades de TI). 


\section{Conclusão}

A aplicação de tecnologias digitais pela sociedade contemporânea continua a ser um tema em pauta atualmente. Entretanto, entende-se que essa temática deve ser rediscutida, considerando os impactos atuais das novas tecnologias em áreas essenciais como educação, trabalho e negócios; além das novas formas de uso das tecnologias pela sociedade, que vem alterando rapidamente hábitos cotidianos, até então, tradicionais.

Nesse cenário, o processo de mudança conhecido como transformação digital deve ser uma questão prioritária para as organizações e seus gestores, além da sociedade. Embora o escopo dessa transformação seja amplo e envolva diferentes áreas do conhecimento, entende-se que a Ciência da Informação pode contribuir nesse processo, no seu papel de organizadora da informação para efetiva comunicação do conhecimento.

Entretanto, a mudança rumo à efetiva transformação digital é desafiadora. No caso dos indivíduos, eles precisam instruir-se sobre o tema, estarem preparados e inseridos nesse contexto para continuarem exercendo seus direitos de cidadania. No que tange às empresas, a necessidade perpassa as tecnologias adotadas, pois necessitam empregar esforços na elaboração e aplicação de estratégias para se manterem competitivas e em boas condições de sobrevivência e concorrência no mercado.

Considerando estes argumentos, a presente pesquisa apresentou e discutiu os principais conceitos sobre o processo de transformação digital nas organizações, destacando, principalmente, o uso e aplicação de ontologias como parte da estratégia das organizações para aderirem à transformação digital. $\mathrm{Na}$ presente pesquisa, mostrou-se que as ontologias podem contribuir com o processo de desenvolvimento de produtos (PDP) das empresas, assim como auxiliam o processo de construção da nuvem de serviços de uma empresa.

No processo de desenvolvimento de produtos, as ontologias ajudam a tornar mais explícito o conhecimento adquirido de um certo domínio, pois permitem representar melhor as informações no processo de transição entre o projeto e o desenvolvimento do produto. Também, aportam a verificação de 
conformidade dos requisitos com o produto em desenvolvimento, além de resolverem alguns problemas de integração entre sistemas e de interoperabilidade semântica.

Avaliou-se que a migração dos serviços oferecidos por uma empresa para uma estrutura em nuvem é, atualmente, uma estratégia apropriada para que as empresas possam reduzir custos com infraestrutura, softwares, entre outros serviços, e também, para obter mais segurança e confiabilidade das informações armazenadas na nuvem. Apesar disso, é possível perceber que, embora existam inúmeros serviços em nuvem disponíveis, muitas empresas ainda buscam explorar todo o potencial da nuvem. Os tomadores de decisões nas empresas, muitas vezes, não possuem o conhecimento necessário sobre como os serviços em nuvem podem impulsionar seus negócios. Cabe esclarecer que as ontologias não irão solucionar esse problema, que depende dos próprios gestores, mas podem contribuir no processo de suporte na criação da nuvem de serviços.

Foram apresentadas as ontologias corporativas SOA Ontology e ESARC, que representam conceitos básicos, terminologia e semântica de uma arquitetura orientada a serviços, sendo úteis aos arquitetos corporativos que precisam compartilhar suas informações com base em conceitos explicitamente definidos. Já com o método Latter, o modelo de negócio organizacional pode ser ampliado, utilizando serviços digitais. Estas representações possibilitam uma compreensão clara dos conceitos arquitetônicos integrados e fornecem, ainda, mecanismos adicionais de representação e inferência do conhecimento.

Outra possibilidade de aplicação de ontologias no processo de transformação digital, refere-se ao seu uso para representar e compartilhar informação no modelo de rede da Internet das Coisas (IoT). Essa aplicação já é uma realidade em algumas empresas que utilizam ontologias corporativas para representar as informações da enorme quantidade de objetos de IoT, dinamicamente crescente. A integração e gerenciamento desse grande número de objetos é um dos desafios atuais da implementação da IoT. A utilização de ontologias no modelo de rede da IoT é um tema de pesquisa de relevância nos dias atuais, uma vez que pode influenciar as estratégias digitais. Cada vez mais, novos sistemas de informação empresariais estão integrando infraestruturas e 
componentes emergentes. A utilização e aplicação de ontologias no âmbito da IoT fica como sugestão de continuidade do presente estudo.

Por fim, é importante ressaltar que uma necessidade emergente dos gestores é pesquisar, discutir e aplicar estratégias organizacionais, que incluam artefatos tais como ontologias, arquiteturas corporativas, ferramentas para modelagem de negócio, tecnologias em nuvem, entre outras. Assim, eles poderão contribuir para que as empresas estejam preparadas para seu processo de transformação digital. Decerto, essa é uma questão vital de sobrevivência e competitividade para as empresas.

\section{Referências}

ALVARENGA, L. Representação do conhecimento na perspectiva da Ciência da Informação em tempo e espaços digitais. Encontros Bibliográficos: Revista Eletrônica de Biblioteconomia e Ciência da Informação, Florianópolis, v. 8 n. 15, p. 18-40, 2003.

BARRETO, A. M. Informação e conhecimento na era digital.

Transinformação, Campinas, v. 17, n. 2, p. 111-122, maio/ago. 2005.

BERNERS-LEE, T.; HENDLER, J.; LASSILA, O. The semantic web.

Scientific American, New York, v. 5, p. 1-4, 2001.

BHARADWAJ, A. et al. Digital business strategy: toward a next generation of insights. MIS Quarterly, Minneapolis, MN, USA, v. 37, n. 2, p. 471-482, 2013.

BLACKBURN, S. The Oxford dictionary of philosophy. Oxford: Oxford University Press, 1996.

BORST, W. N. Construction of engineering ontologies for knowledge sharing and reuse. 1997. Tese (Doutorado em Sistemas de Informação e Conhecimento) - University of Twente, Twente, NL, 1997.

BRASIL. Ministério do Planejamento, Desenvolvimento e Gestão. Governo Digital. Interoperabilidade. Brasília: MP, 2017. Disponível em:

$<$ https://www.governodigital.gov.br/eixos-deatuacao/governo/interoperabilidade>. Acesso em: 22 abr. 2018.

BREITMAN, K. K. Web semântica: a internet do futuro. Rio de Janeiro: LTC, 2005. 
CASTILLA, A. C. Instrumento de investigação clínico-epidemiológica em cardiologia fundamentado no processamento de linguagem natural. 2007. Tese (Doutorado em Cardiologia) - Faculdade de Medicina da Universidade de São Paulo, São Paulo, 2007.

D'ANDRÉA, C. F. Estratégia de produção e organização de informações na web: conceitos para a análise de documentos na internet. Ciência da Informação, Brasília, v. 35, n. 3, p. 39-44, 2006.

DATTA, S. Emergence of digital twins: is this the march of reason? Cambridge: Massachusetts Institute of Technology, 2016. Disponível em: <https://dspace.mit.edu/handle/1721.1/104429>. Acesso em: 22 out. 2017.

FICHMAN, R.; SANTOS, B.; ZHENG, Z. Digital innovation as a fundamental and powerful concept in the information systems curriculum. MIS Quarterly, Minneapolis, v. 38, n. 2, p. 329-353, 2014.

FITZGERALD, M. et al. Embracing digital technology: a new strategic imperative. Cambridge: MIT Sloan Management Review, 2013.

FONSECA, F.; MARTIN, J. Learning the Differences Between Ontologies and Conceptual Schemas Through Ontology-Driven Information Systems. Journal of the Association for Information Systems, v. 8, Issue 2, Article 4, 2007.

FRANK, M.; ROEHRIG, P.; PRING, B. Code halos: how the digital lives of people, things, and organizations are changing the rules of business. Hoboken, New Jersey: Wiley, 2014.

GARTNER. Gartner says 4.9 billion connected "things" will be in use in 2015. Barcelona: Gartner, 2014.

GÓMEZ, M. N. G. Novas fronteiras tecnológicas das ações de informação: questões e abordagens. Ciência da Informação, Brasília, v. 33, n. 1, p. 55-67, jan./abr. 2004.

GRÜBER, T. R. Towards principles for the design of ontologies used for knowledge sharing. Palo Alto: Stanford Knowledge Systems Laboratory, 1993.

JAVAID, A. et al. Enabling digital transformation in SMEs by combining enterprise ontologies and service blueprinting. In: INTERNATIONAL CONFERENCE ON SERVICEOLOGY, 5., 2017, Vienna, Austria.

Proceedings... Berlin, Heidelberg: Springer, 2017. p. 224-233.

LAKATOS, E. M.; MARCONI, M. de A. Metodologia científica. 7. ed. São Paulo: Atlas, 2017.

LUCAS, H. C. et al. Impactful research on transformational information technology: an opportunity to inform new audiences. MIS Quarterly, 
Minneapolis, v. 37, n. 2, p. 371-382, 2013.

MARKETSANDMARKETS. Digital Transformation Market by Solution \& Service - 2020. Hadapsar: MarketsandMarkets, 2015.

McDONALDS, M.; RUSSEL-JONES, A. The digital edge: exploiting information and technology for business advantage. Stamford: Gartner, 2012. Ebook.

MICHEL, M. H. Metodologia e pesquisa científica em ciências sociais. 3. ed. São Paulo: Atlas, 2015.

MIKA, P. Social networks and the semantic web. New York: Springer, 2007.

OPEN BIOLOGICAL AND BIOMEDICAL ONTOLOGY. The OBO Foundry. 2017.

OPEN GROUP. SOA reference architecture. San Francisco: The Open Group, 2018.

PATEL, K.; McCARTHY, M. Digital transformation: the essentials of ebusiness leadership. New York: McGraw-Hill Professional, 2000.

PEREIRA, C.; SOARES, A. Ontology development in collaborative networks as a process of social construction of meaning. In: OTM CONFEDERATED INTERNATIONAL CONFERENCES "ON THE MOVE TO MEANINGFUL INTERNET SYSTEMS": OTM 2008 WORKSHOPS, 2008, Proceedings... Berlin, Heidelberg: Springer-Verlag, 2008. p. 605-614.

RAMALHO, R. R. A. S.; VIDOTTI, S. A. B. G. R.; FUJITA, M. N. S. L. Web semântica: uma investigação sob o olhar da ciência da informação.

DataGramaZero, João Pessoa, v. 8, n. 6, p. A04-0, 2007.

ROZENFELD, H. et al. Gestão de desenvolvimento de produtos: uma referência para a melhoria do processo. São Paulo: Saraiva, 2006.

SANTOS, P.; MASSÓ, J. M. Rumo a uma nova realidade transformada. UNO Desenvolvendo Ideias, São Paulo, n. 24. p. 29-30, 2016.

SCHULZ, S. et al. Strengths and limitations of formal ontologies in the biomedical domain. RECIIS - Electronic Journal Communication Information \& Innovation in Health, Rio de Janeiro, v. 3, n. 1, p. 31-45, mar. 2009.

SMITH, B. Ontology and information systems. Buffalo: State University of New York at Buffalo, 2004.

SMITH, B. et al. The OBO foundry: coordinated evolution of ontologies to 
support biomedical data integration. Nature Biotechnology,

Bethesda MD, USA, v. 25, n. 11, p. 1251-1255, 2007.

SMITH, B.; WELTY, C. Ontology: towards a new synthesis. In:

INTERNATIONAL CONFERENCE ON FORMAL ONTOLOGY IN INFORMATION SYSTEMS, 2001, New York. Proceedings... New York: ACM Press, 2001. p. 3-9.

SOERGEL, D. Functions of a thesaurus / classification / ontological knowledge base. Maryland: College of Library and Information Services, University of Maryland, 1997.

SOMMERVILLE, I. Engenharia de software. 9. ed. São Paulo: Pearson, 2011.

SZEJKA. A. et al. Proposal of a model-driven ontology for product development process interoperability and information sharing. In: INTERNATIONAL CONFERENCE ON PRODUCT LIFECYCLE MANAGEMENT, 13., 2016, Columbia. Proceedings... Columbia: Springer, 2016. p. 158-168.

TOLBOOM, I. The impact of digital transformation. 2016. $101 \mathrm{f}$. Master Thesis Report (Master in System Engineering, Policy analysis and Management) - Faculty of Technology, Policy and Management, Delf University of Technology, Delft, 2016.

USCHOLD, M.; GRUNINGER, M. Ontologies: principles, methods and applications. Knowledge Engineering Review, Cambridge, v. 11, n. 2, p. 93136, 1996.

VICKERY, B. C. Ontologies. Journal of Information Science, Thousand Oaks, CA, USA, v. 23, n. 4, p. 277-286, 1997.

VILLALOBOS, A. P. de O.; SILVA, D. S. As potencialidades da web semântica para a ciência da informação. Ponto de Acesso, Salvador, v. 4, n. 2, p. 58-75, set. 2010 .

W3C. Semantic web. 2017. Disponível em:

<https://www.w3.org/standards/semanticweb/>. Acesso em: 26 set. 2017.

WALESKA, M. Tendências da nova economia: paradigmas da era digital. UNO Desenvolvendo Ideias, São Paulo, n. 24, p. 31-33, 2016.

WESTERMAN, G.; CALMEJANE, C.; BONNET, D. Digital transformation: a roadmap for billion-dollar organizations. [S.1.]: MIT Center for Digital Business, Capgemini Consulting, 2011. p. 1-68.

WORLD ECONOMIC FORUM. World Economic Forum Annual Meeting. 2016. 
ZARZALEJOS, J. A. Cidadania digital. UNO Desenvolvendo Ideias, São Paulo, n. 24, p. 11-13, 2016.

ZIMMERMANN, A. et al. Digital enterprise architecture: transformation for the internet of things. In: INTERNATIONAL ENTERPRISE DISTRIBUTED OBJECT COMPUTING WORKSHOP , 19., 2015, Adelaide, SA, Austrália. Proceedings... Adelaide: IEEE, 2015.

\title{
Ontologies for information organization in digital transformation processes
}

\begin{abstract}
Nowadays, the application of digital technologies by contemporary society and in organizations has become so frequent and expanded that it has been characterized as a change process called digital transformation. The aim of this paper is to discuss the concepts and processes of digital transformation to be used as strategies in organizations, focusing on the use and application of ontologies in this context and on the current challenges of its application. In this research, ontologies are treated as instruments for knowledge representation and organization in different domains, in the context of Information Science. It was used an exploratory research methodology with a qualitative approach, through which was carried out the study of the scientific literature, the selection of the art state and the subjective analysis. The results indicated that ontologies allow to represent information in the transition process between the project and the product development, acting as the solution of semantic interoperability problems. Ontologies are also useful in the process of constructing a company's services cloud, by representing the basic concepts, terminology and semantics of a service-oriented architecture. Finally, it was concluded that ontologies are useful in the companies' processes of digital transformation and product development, because they make the acquired knowledge of a certain domain explicit, allowing a clearer understanding of the integrated architectural concepts and providing additional mechanisms for knowledge inference.
\end{abstract}

Keywords: Digital transformation. Ontologies. Digitalization. Organizations.

Recebido: $13 / 02 / 2018$

Aceito: 11/05/2018

\footnotetext{
1 O Consórcio World Wide Web busca agregar partes interessadas, em um processo eficaz para desenvolver padrões de alta qualidade para a web. (W3C, 2017).

2 Google Docs é um pacote de aplicativos do Google que funciona totalmente on-line, diretamente no browser, compatíveis com o Office da Microsoft.

3 A Internet das Coisas (IoT) é um sistema de dispositivos (objetos do dia-a-dia), mecânicos ou digitais, providos de identificadores únicos, com a capacidade computacional de serem acessados na internet.
} 